\title{
REFLEXÕES SOBRE A PRÁXIS NO PROCESSO FORMATIVO DO PROFISSIONAL ENFERMEIRO
}

\author{
Caroline Venturin Guarinão, Raimunda Abou Gebran \\ Universidade do Oeste Paulista - UNOESTE, Programa de Pós Graduação em Educação, Presidente Prudente, SP. E- \\ mail: carolineguarinao@gmail.com.
}

\begin{abstract}
RESUMO
A formação dos profissionais da saúde tem sido amplamente discutida e problematizada quanto a sua efetiva contribuição no contexto social em que atuam. Assim, o presente artigo tem por objetivo analisar como se configura a relação teoria e prática na formação do profissional enfermeiro. Para tanto buscou-se uma revisão bibliográfica que aborda essa temática, procurando em um diálogo de autores da área educacional e da área de enfermagem contemplar a importância desse processo interativo que contribui para a formação de um profissional critico e reflexivo que contribuirá para uma ação compromissada e competente no contexto social de sua prática profissional.
\end{abstract}

Palavras-chave: Teoria e Prática. Ação docente. Enfermagem. Formação Profissional

\section{OBSERVATIONS ON THE INTERACTION BETWEEN THEORETICAL AND PRACTICAL RELATIONS IN NURSING EDUCATION.}

\begin{abstract}
Education of health care professionals has been largely discussed and problematized regarding its effective contribution to the social context in which they work on. In such case, this article has as an objective to analyze how the theoretical and practical relations in the education of health care professionals are established. In order to achieve the objective, a bibliographic review that addresses this theme was used, searching for a dialogue of authors from the education and nursing area to contemplate the importance of this interactive process that contributes to the education of a critical and reflective professional who will contribute to a committed and competent action in the social context of its professional practice.
\end{abstract}

Keywords: Theory and Practice. Teaching action. Nursing. Professional qualification. 


\section{INTRODUÇÃO}

Este estudo é resultado do processo de vivências e inquietações formuladas no decorrer de minha formação como enfermeira, na qualidade de estudante, bem como de minha atuação profissional e docente em um curso de graduação em Enfermagem. A vivência destas práticas fez com que refletisse sobre a relação teoria e prática na formação do profissional enfermeiro crítico e reflexivo, relação esta, que reflete diretamente na sua formação e atuação.

Nessa perspectiva, compreendemos que a discussão sobre a formação do enfermeiro, no contexto contemporâneo vem passando por transformações pedagógicas que são intermediadas pela Lei de Diretrizes e Bases da Educação (LDB)- lei $n^{\circ}$ 9394/96, que ressalta, dentre os propósitos da Educação Superior está à indispensabilidade de estimular a formação de profissionais com espírito científico e pensamento reflexivo, objetivos que são reforçados pelas Diretrizes Curriculares Nacionais (DNC) do curso de Graduação em Enfermagem (BRASIL. Ministério da Educação, 2001).

A Resolução CNE/ CES no 3, de 7 de novembro de 2001, que instituiu as Diretrizes Curriculares Nacionais do Curso de Graduação em Enfermagem enfatiza que a formação do profissional enfermeiro deva ocorrer de forma que os conhecimentos teóricos e práticos sejam desenvolvidos de forma articulada ao longo do curso (BRASIL, 2001)

Conforme Cruz (2017) a formação dos profissionais da saúde, principalmente, a do enfermeiro, foi historicamente influenciada pelo emprego de métodos assistencialistas, focalizada em abordagens conservadoras, fragmentadas e reducionistas, com a ênfase no saber curativista em detrimento de ações proativas que enfatizem a proteção e promoção da saúde.

Assim, compreendemos que a formação do profissional enfermeiro não deve estar embasada na racionalidade técnica, mas precisa envolver uma prática reflexiva que se entende como a reflexão sobre a situação, os objetivos, os meios, o lugar, operações envolvidas, resultados provisórios e evolução previsível do sistema de ação envolvendo a reflexão na ação que consiste em preparar o profissional para refletir de forma mais ágil durante a ação.

Durante o exercício da profissão docente na formação do enfermeiro podemos perceber como é importante a atuação do mesmo na construção dos conhecimentos. Portanto, o professor, ao assumir uma abordagem pedagógica que permita ao aluno, futuro enfermeiro, compreender a sua ação em uma perspectiva social e política, propiciará caminhos para a construção de sua identidade profissional.

A formação dos profissionais da saúde tem sido amplamente discutida e problematizada quanto a sua efetiva contribuição no contexto social em que atuam, assim, o presente artigo tem por objetivo analisar como se configura a relação teoria e prática na formação do profissional enfermeiro crítico e reflexivo em curso de Graduação de Enfermagem.

\section{METODOLOGIA}

Neste trabalho apresentaremos uma revisão bibliográfica, no que tange a temática, buscando estabelecer uma articulação entre os autores da área educacional e os da área da enfermagem contemplando a importância da práxis no processo de formação do profissional enfermeiro.

A revisão bibliográfica foi realizada nas bases de dados do portal da Capes (teses e dissertações), da Biblioteca Virtual em Saúde (LILACS, MEDLINE, SciELO), abrangendo trabalhos publicados no ano de 2000 a 2015. Os descritores utilizados foram: Teoria e Prática, Enfermagem, Formação Profissional, formação crítica e reflexiva. Serão apresentadas reflexões que evidenciam as premissas filosóficas e epistemológicas que compõem a análise da relação que se estabelece entre teoria e prática. Abordaremos também, como a compreensão desta relação constitui-se como fundamental para a formação de profissionais críticos e reflexivos. Discutiremos tais 
aspectos à luz dos estudos de Imbernón (2000), Schon(2000), Contreras (2002), e Pimenta (2005), Gamboa (2010) e Baptista (2010) Nascimento (2015).

\section{RESULTADOS E DISCUSSÕES}

Teoria e prática são duas categorias que no âmbito científico tendem a indicar sempre uma relação. No entanto, a literatura nem sempre apresenta um consenso sobre a interpretação dessa relação. Existem algumas tendências que defendem a teoria mediante a prática, já outras, apontam que a prática confere validez à teoria. (GAMBOA, 2010).

Essa discussão sobre a dualidade da relação sobre estas categorias tende a ser superada quando se adota a análise da relação dinâmica entre elas. Conforme os estudos de Gamboa (2010) quem denomina esta dinâmica é o termo práxis. Em contraposição a outras tendências que buscam equilibrar a relação entre as categorias teoria e prática, o termo práxis tenciona, contradiz e confronta esta relação. Podemos dizer então que a práxis produz uma relação dialética entre as categorias.

Nas palavras de Gamboa (2010, p. 1) “[...] a teoria transforma-se na negação da prática porque a tenciona: a prática coloca em xeque a teoria, porque em vez de ajustar a ela, transformase em seu contrário". Diante disso, compreendemos que existe uma relação dialética entre ambas. Os pressupostos dialéticos entendem a articulação entre as categorias na contradição e nos processos conflituosos. Assim, na concepção dialética não podemos conceber a teoria separada da prática, pois não "[...] pode existir uma teoria solta, o que existe é sempre a teoria de uma prática" (GAMBOA, 2010, p. 7).

Nessa perspectiva, entendemos que a prática existe como a prática de uma dada teoria e a relação que se estabelece entre elas é que vai possibilitar a sua existência. É importante ressaltar também que há uma necessidade premente no processo dialético de articulação da relação teoria e prática com os contextos históricos sociais reais, pois estes contextos é que darão sentido para a relação estabelecida entre as categorias.

Segundo Gramsci (1999) a Filosofia da Práxis parte da crítica a toda possibilidade de analisar uma ação prática como um fato isolado, ou como uma ação em si mesma. Uma análise deste tipo não segue os preceitos da dialética que indicam como um dos princípios a análise da totalidade. Analisar a relação entre teoria e prática a partir da dialética indica o cuidado de não realizar análises fragmentadas, incompletas e destoadas da realidade.

Diante disso, Gamboa complementa esta ideia quando expõe que:

[....] a prática deve ser entendida no contexto de uma formação social historicamente concretizada, e, como tal, prenhe de pressupostos, interesses, racionalizações, determinações econômico-sociais e referências político-culturais. Toda teoria por sua vez, além de ser a racionalização de uma prática, e constituir-se também em instrumental da prática, na medida em que presta auxilio para a solução de problemas concretos, deve ser fundamentalmente crítica da prática na medida em que a questiona constantemente (GAMBOA, 2010, p. 9, grifo nosso)

A partir do que o autor expõe entendemos que para analisar a relação que se estabelece entre teoria e prática numa perspectiva dialética é preciso que exista a prática de questionamento e crítica no processo à luz do contexto histórico e social passado e presente.

Nas palavras de Baptista (2008, p. 196):

0 processo de humanização encontra-se dialeticamente vinculado à relação teoria e prática, uma vez que através da prática social o homem tem produzido cultura e, consequentemente, a si mesmo, objetivando-se. 
Essa objetivação gera novas necessidades e a produção de novas objetivações, novas ideias e novas ações.

A constituição do professor, enquanto sujeito social e humano vincula-se à compreensão acerca dessa relação entre teoria e prática embasada na práxis. A sua objetivação sugere uma ponderação crítica acerca do papel que desenvolve no processo educativo, que, por conseguinte, alude tanto a aproximação teoria e prática, questionando suas proposições, quanto o enfrentamento da retificação da teoria e da prática (BAPTISTA, 2008).

Nesse sentido, torna-se imperioso que o professor se aproprie dos instrumentos necessários à compreensão de que a prática pedagógica, enquanto relação de hegemonia encontra-se inserida em um determinado projeto de educação, determinado por uma dada sociedade.

Nesse viés de pensamento a teoria e a prática passam a ser compreendidas como construção humana e não como algo já pronto, tornando possível pensar a construção de uma nova educação voltada para uma nova sociedade.

Assim, entendemos que a Universidade é, portanto, um dos espaços que tem o papel de favorecer o pensar filosófico, sendo lócus onde o estudante realiza a reflexão crítica sobre sua própria prática, sobre os problemas éticos, jurídicos, religiosos e morais, que possibilitam a reunificação entre teoria e prática.

Nesse contexto, torna-se premente a análise das contradições e a abertura de espaços em que sejam discutidos de maneira crítica a construção de concepções que promovam a emancipação social e humana.

Portanto, as premissas curriculares que permeiam a construção do currículo de formação dos profissionais devem estar pautadas na práxis, no sentido de entender de maneira dialética como o profissional pode atuar relacionando os aspectos da teoria e da prática.

Nas palavras de Candau e Lelis (1999), no que tange a formação dos profissionais no contexto do ensino superior, a relação entre teoria e prática pode ser embasada de duas formas: a primeira sustentada em uma perspectiva dicotômica e a segunda indicando uma visão de unidade. A visão dicotômica refere-se à fragmentação e distanciamento entre teoria e prática tornando-se componentes totalmente isolados; frases como "uma coisa é a teoria, outra, a prática" e "na prática a teoria é outra" enfatizam esse significado. Na visão de unidade, teoria e prática são dois componentes indesatáveis, devendo estar lado a lado, completando-se.

Para Hengemühle (2007) relacionar teoria e prática é uma dificuldade que ocorre historicamente nas práticas pedagógicas dos docentes, existe uma complexidade em unir a teoria ao contexto, para que ocorra a significação e solução dos problemas. Nesse processo, o professor, como mediador, deverá estimular a participação dos alunos, favorecer a articulação teoria e prática, propiciando o desenvolvimento do pensamento crítico e reflexivo.

Segundo Badaró (2005) a formação do senso crítico está ligada a uma alteração qualitativa da maneira de pensar e entender o mundo; esta alteração provoca uma reinterpretação e o enriquecimento do conhecimento já existente. Assim,

A proposta deste novo conhecimento demonstra que o mundo é cognoscível pelo homem. O mundo verdadeiro da teoria, por oposição ao mundo aparente do conhecimento comum e do realismo ingênuo, modifica a maneira de aprendermos a realidade. O sujeito cognoscente deve analisar de modo crítico a realidade, uma análise de conceitos científicos, a fim de evidenciar o crescimento dialético ao sujeito e a possibilidade de aproximações entre o sujeito e o objeto são inesgotáveis (BADARÓ, 2005, P.35) 
Contrariando o senso comum que segundo o mesmo autor (Badaró 2005, p.22) "encontrase um pensar, um saber, que é usado e reproduzido de forma mecânica, sem que disso se tenha consciência, concepções que muitas vezes são impostas pelo meio externo ou determinada tradição"

Assim, entendemos que para que exista a superação do senso comum a educação deve exercer seu papel, contribuindo para uma aprendizagem que desenvolva a reflexão crítica. Segundo Fernandes et al. (2009) as ações pedagógicas devem condizer com o equilíbrio entre teoria e prática para construção das competências de tomada de decisão, comunicação, liderança, administração e gerenciamento e educação permanente; para que docentes e discentes sejam estimulados a buscar novos conhecimentos em resposta às questões colocadas pela prática.

Portanto, é compromisso do educador, por meio de uma relação dialógica, não trabalhar saberes fragmentados, mas trazer os educandos para um contexto mais amplo. É atribuído ao educador apontar relações entre os variados saberes, contextos, práticas e as possíveis consequências para a profissão, para a saúde, para a qualidade de vida das pessoas e para a prática político-social.

O educador precisa refletir junto aos educandos sobre a teoria e prática, procurando compreendê-las de modo criativo e crítico, além de procurar despertar a inteligência do aluno, ajudando-o no seu processo de formação, ou seja, o desenvolvimento de um ensino interativo e dialógico com os alunos e na relação com os conhecimentos culturais e sociais e que possam proporcionar espaços de participação, reflexão e pesquisa. (NASCIMENTO et al., 2008).

A educação necessita de profissionais comprometidos com a preparação dos seus alunos, como diz Imbernon (2009, p. 18):

A formação assume um papel que vai além do ensino que pretende uma mera atualização científica, pedagógica e didática e se transforma na possibilidade de criar espaços de participação, reflexão e formação para que as pessoas aprendam e se adaptem para poder conviver com a mudança e com a incerteza.

É nesse sentido de construir um profissional capaz de pensar, refletir o seu agir que Schön (2000) aborda a importância do profissional reflexivo, que possa ter a capacidade de trabalhar com reflexões diante das situações problemas, se adaptando às alterações que surgem no seu meio de trabalho. $\mathrm{O}$ autor enfatiza a aprendizagem por meio do fazer, de modo que não pode ser ensinado ao aluno aquilo que é necessário ele saber, mas é possível instruí-lo.

Ele tem que enxergar, por si próprio e à sua maneira, as relações entre meios e métodos empregados e resultados atingidos. Ninguém mais pode ver por ele, e ele não poderá ver apenas 'falando-se' a ele, mesmo que o falar correto possa guiar seu olhar e ajudá-lo a ver o que ele precisa ver" (SCHÖN, 2000, p.25).

O autor apresenta uma nova teoria de conhecimento da prática fundamentando-se nos princípios de conhecimento na ação e reflexão na ação. O conhecimento na ação é um elemento relacionado com o saber-fazer, é espontâneo e que surge na ação, ou seja, é um conhecimento tácito. Sendo assim, a reflexão se revela a partir de situações imprevistas produzidas pela ação e nem sempre o conhecimento na ação é suficiente.

\section{CONCLUSÃO}

A partir das considerações encontradas nos estudos compreendemos que a reflexão se revela em três sentidos: a reflexão sobre a ação que se compõe em pensarmos sobre o que foi feito; a reflexão na ação que é refletirmos no meio da ação de forma ininterrupta através da condução do pensamento dando forma ao que estamos fazendo, tendo a oportunidade de 
interferir na situação em desenvolvimento; e a reflexão sobre a reflexão na ação, que se refere ao pensar sobre a reflexão-na-ação pregressa, estabelecendo entendimento sobre determinada situação viabilizando a adesão de novas estratégias.

Entendemos também que esse processo vincula-se a análise da relação teoria e prática a partir da premissa dialética, pois exige que o sujeito reflita sobre sua ação analisando a totalidade, os conflitos, os tensionamentos sociais e históricos que influenciam a prática e a partir daí possa compreender como buscar na teoria elementos que os levem a formulação da síntese, ou seja, produção do conhecimento por meio de uma base reflexiva.

\section{REFERÊNCIAS}

BADARÓ, C. E. Epistemologia e Ciência: reflexão e prática na sala de aula. Bauru, SP: Edusc, 2005

BAPTISTA, Maria das Graças de Almeida. A concepção do professor sobre sua função social: das práticas idealistas à possibilidade de uma ação crítica. 2008. 245f. Tese (Doutorado em Educação) - Universidade Federal da Paraíba, João Pessoa, 2008.

BRASIL. Ministério da Educação. Resolução CNE/CES n‥ 3, de 07 de novembro de 2001. Institui as Diretrizes Curriculares Nacionais do Curso de Graduação em Enfermagem. Brasília: Diário Oficial da União; 2001. Disponível em: <http://portal.mec.gov.br/cne/arquivos/pdf/CES03.pdf>. Acesso em: Março. 2015.

BRASIL. Ministério da Educação. Lei de Diretrizes e Bases da Educação Nacional. Lei n. 9.394/96.Brasília, DF: MEC/SEF, 1996.

CANDAU, V.M. \& LELIS, I.A. A Relação Teoria-Prática na Formação do educador. In: CANDAU, V.M (Org.). Rumo a uma Nova Didática. 10 ed. Petrópolis: Vozes. 1999.

CONTRERAS, J. A autonomia de professores. 2. ed. São Paulo: Cortez, 2002.

CRUZ, Ronny Anderson de Oliveira et al . Reflexões à luz da Teoria da Complexidade e a formação do enfermeiro. Rev. Bras. Enferm., Brasília, v. 70, n. 1, p. 236-239, Fev. 2017. Disponível em: $<$ http://www.scielo.br/scielo.php?script=sci_arttext\&pid=S003471672017000100236\&lng=en\&nr m=iso>. Acesso em: 04 Junho. 2017.

FERNANDES, Josicelia Dumêt et al. Estratégias para a implantação de uma nova proposta pedagógica na escola de enfermagem da Universidade Federal da Bahia.Rev. bras. enferm., Brasília, v. 56, n. 4, p. 392-395, Agosto. 2003. Disponível em:

<http://www.scielo.br/pdf/reben/v56n4/a17v56n4.pdf >. Acesso em: 04 Junho. 2015

GAMBOA, Silvio Áncizar Sánchez O debate da pós-modernidade: as teorias do conhecimento em jogo. Filosofia e Educação (Online), ISSN 1984-9605 - Revista Digital do Paideia Volume 2, Número 2, Outubro de 2010 - Março de 2011

GRAMSCI, A. Cadernos do cárcere. Antonio Gramsci: introdução ao estudo da filosofia. A filosofia de Benedetto Croce. Ed. e trad. de Carlos N. Coutinho. Coed. de Luiz S. Henriques e Marco A. Nogueira. Rio de Janeiro: Civilização Brasileira, 1999. v. 1.

HENGEMÜHLE, Adelar. Formação de professores: da função de ensinar ao resgate da educação. Petrópolis, RJ: Vozes, 2007 
IMBERNÓN, F. A educação no século XXI: os desafios do futuro imediato. 2. ed. Porto Alegre: Artes Médicas Sul, 2000.

NASCIMENTO, Estelina Souto do; SANTOS, Geralda Fortina dos; CALDEIRA, Valda da Penha; TEIXEIRA, Virgínia M. Nascimento. Formação por competência do enfermeiro: reflexão sobre a alternância-teoria e prática, profissionalização e pensamento complexo. Rev. Brasileira de Enfermagem, v. 56, n.4. p. 447-452. 2003. Disponível em:<http://www.scielo.br/pdf/reben/v56n4/a30v56n4.pdf>. Acesso em: Abril 2015.

SCHÖN, D. A. Educando o profissional reflexivo: um novo design para o ensino e aprendizagem. Porto Alegre: Artes Médicas Sul, 2000. 